\title{
Evaluation of Anti-microbial, Hypoglycemic and Anti-diarrheal activities of Setaria italica Seeds
}

\section{Tumpa Dasgupta, Amlan Ganguly, Muhammad Asaduzzaman and Nazmul Qais}

\author{
Department of Clinical Pharmacy and Pharmacology, Faculty of Pharmacy, \\ University of Dhaka, Dhaka-1000, Bangladesh
}

Received: March 30, 2016; Accepted: June 02, 2016; Published (web): June 20, 2016

\begin{abstract}
The ethanolic crude extract of Setaria italica seeds (Poaceae) was investigated for its possible anti-microbial, hypoglycemic and anti-diarrheal activities. Anti-microbial activity was evaluated by disc diffusion method while the hypoglycemic and anti-diarrheal properties were determined by oral glucose tolerance test and castor oil induced diarrheal method, respectively in Albino mice. The ethanolic extract and its different fractions of $S$. italica have shown good antimicrobial activity against gram negative bacteria having zone of inhibition 9-13 mm (ciprofloxacin: 40$41 \mathrm{~mm}$ ). In evaluation of hypoglycemic activity, ethanolic extract and its chloroform fraction, at 400 $\mathrm{mg} / \mathrm{kg}$, also showed promising hypoglycemic property having blood glucose level of 3.74 and 3.72 $\mathrm{mmol} / \mathrm{l}$ after 120 minute, respectively when compared to standard glibenclamide $(3.44 \mathrm{mmol} / \mathrm{l})$. On the other hand, during the assessing for anti-diarrheal activity, the crude extract did not significantly reduce the frequency of defecation. The findings of the studies demonstrate anti-microbial and hypoglycemic properties of S. italica.
\end{abstract}

Keywords: Poaceae, Setaria italica, anti-microbial, disc diffusion, hypoglycemic, antidiarrheal, castor oil.

\section{INTRODUCTION}

Setaria italica (foxtail millet), Bengali name kaoun or kakun belongs to the family Poaceae It is traditionally used for its anti-inflammatory activity $^{1}$ and now praised as a grain with low glycemic index. ${ }^{2}$ S. italica was domesticated from the wild Setaria viridis in East Asia more than 7000 years ago. ${ }^{3}$ Foxtail millet is now-a-days a minor crop in SE Europe, parts of Asia (especially India, China, Bangladesh and Japan) and North Africa. ${ }^{4}$ S. italica is a plant of the temperate and subtropical zones, amenable to cultivation in the tropics where it is found at elevations up to 2,000 meters. It grows best in areas where annual daytime temperatures are within the range of $16-26^{\circ} \mathrm{C}$, but can tolerate up to

Correspondence to: Nazmul Qais

Phone: +88029661900-73; Cell: 01714417750;

E-mail: nqais@yahoo.com

Dhaka Univ. J. Pharm. Sci. 15(1): 31-35, 2016 (June)
$5-35{ }^{\circ} \mathrm{C}$. It is intolerant of frost. It prefers a mean annual rainfall in the range of $500-700 \mathrm{~mm}$, but tolerates 300-4,000 mm. ${ }^{5}$

Despite of having all favorable environmental criteria to grow $S$. italica in Bangladesh and India, it is not cultivated in a large scale. ${ }^{4}$ The aim of our study was to explore some pharmacological properties of the plant that will scientifically validate its traditional claims as well as to encourage people to cultivate it in a large scale. In this study an attempt was undertaken to evaluate the anti-microbial, hypoglycemic and anti-diarrheal properties of the plant by scientific methods and we, here in, report the results of our preliminary investigations.

\section{MATERIALS AND METHODS}

Collection and identification of plant materials. The yellow seeds of S. italica (foxtail millet) belonging to the family Poaceae (also known 
as Gramineae) ${ }^{6}$ were collected from Kurigram in October, 2011. The plant sample was properly authenticated by an expert taxonomist of Dhaka University Herbarium (DUH), where a voucher specimen has been deposited with an accession number of DUSH 1109. The seeds of the plant were sun dried for several days, followed by oven drying for 24 hours at considerably low temperature for better grinding to make coarse powder.

Extraction of the plant material. About $850 \mathrm{gm}$ of the powdered material was soaked in 3.5 liters of ethanol in a 5 liter container. The container with its content was sealed by cotton plug and aluminum foil and extracted for 15 days accompanying occasional shaking and stirring. The whole mixture was then filtered through a cotton bed followed by Whatman No.1filter paper and the filtrate thus obtained was concentrated at $39{ }^{\circ} \mathrm{C}$ with a Heidolph rotary evaporator. The concentrated extract was then air dried to a solid residue (20 gm).

Solvent-solvent partition of crude extract. The crude ethanolic extract of the plant was fractionated according to the modified Kupchun method. ${ }^{7}$ For this $5 \mathrm{gm}$ of ethanol extract was triturated with $90 \mathrm{ml}$ of methanol containing $10 \mathrm{ml}$ of distilled water. This mother solution was partitioned successively with petroleum ether, carbon tetrachloride and chloroform. Then each of the fractions was analyzed separately for the anti-microbial, hypoglycemic and anti-diarrheal properties.

Chemicals. Ethanol, Methanol, Carbon tetrachloride, Chloroform, Petroleum ether, Standard glucose solution, Ciprofloxacin, Loperamide were obtained from Pharmacology Laboratory of Dhaka University. Amber glass reagent bottle, Micropipette (50-200 $\mu \mathrm{l}$ ), Glucometer, Glucose strips, Laminar Air flow, Autoclave and other equipments were also available in the same laboratory.

Experimental animals. Swiss albino mice of either sex weighing 25-30 g were obtained from the animal house of the International Centre for Diarrheal Disease and Research, Bangladesh (ICDDR, B). The animals were housed under standard laboratory conditions (relative humidity 55-65\%, room temperature $23.0 \pm 2.0^{\circ} \mathrm{C}$ and 12 hour light: dark cycle). The animals were fed with standard diet and water ad libitum. The research protocol involving mice has been approved by the Ethical Review Committee, Faculty of Biological Science, University of Dhaka (FBS/DU/09/2011) before the study.

Phytochemical screening. The freshly prepared crude ethanolic extract of $S$. italica seeds was qualitatively tested for the presence of flavonoids, alkaloids, terpenoids, triterpenoids, tannins, phenolics, and reducing sugar by using standard phytochemical procedures. ${ }^{1,8}$

Anti-microbial assay. Anti-microbial screening was performed using disc diffusion method. ${ }^{9}$ The sample (8 $\mathrm{mg}$ from each) was dissolved in $20 \mathrm{~mL}$ of methanol to obtain desired concentration (400 $\mu \mathrm{g} / \mathrm{disc}$ ) in aseptic condition. Sterilized filter paper discs were taken in a blank petridish under laminar hood. Then discs were soaked with $20 \mathrm{~mL}$ methanol solution of each test sample and dried. Standard Ciprofloxacin (30 $\mu \mathrm{g} / \mathrm{disc}$ ) discs were used as positive control and blank discs were used as negative control. The sample discs, standard antibiotic discs and negative control discs were placed gently on marked zones in the agar plates preinoculated with test bacteria and fungi. The plates were then kept in a refrigerator at $4{ }^{\circ} \mathrm{C}$ for about 24 hour to allow sufficient diffusion of materials from discs to surrounding agar medium. The plates were then inverted and kept in an incubator at $37{ }^{\circ} \mathrm{C}$ for 24 hour. The bacterial and fungal strains used for the experiment were collected as pure cultures from the Institute of Nutrition and Food Science (INFS), University of Dhaka, Bangladesh. Both gram positive, gram negative organisms and fungi were taken for the test.

Hypoglycemic activity assay. Hypoglycemic activity was evaluated by glucose oxidase method using UV spectrophotometer at $546 \mathrm{~nm}$. In this method, at zero hour test samples, control (1\% Tween-80 solution in saline) and glibenclamide were administered orally by means of a long needle with a ball-shaped end. After 60 minutes, all groups were treated with $10 \%$ glucose solution $(2 \mathrm{gm} / \mathrm{kg}$ 
body weight). Then after 30, 90 and 150 minutes of glucose loading, blood samples were collected from tail vein. Serum was separated using a centrifuge machine at $4000 \mathrm{rpm}$ and the concentration of glucose in blood was measured by glucose oxidase method. ${ }^{10}$

Assay for anti-diarrheal activity. The method, described by Shoba and Thomas, ${ }^{11}$ was followed for this study with slight modification. The animals were divided into negative control, positive control, and test groups containing five mice in each group. The negative control group received vehicle (1\% Tween 80 in water) at the dose of $10 \mathrm{~mL} / \mathrm{kg}$ orally. The positive control group received loperamide at 50 $\mathrm{mg} / \mathrm{kg}$ orally and the test groups received the ethanol extract at the dose of 200 and $400 \mathrm{mg} / \mathrm{kg}$ p.o. A 30 minute interval was given to ensure proper absorption of the administered substances. Then, $1 \mathrm{~mL}$ of castor oil was given to each mouse for inducing diarrhea. Each animal was placed in an individual cage, the floor of which was lined with blotting paper. Each of the mice was observed for 4 hours.

The floor lining was changed every hour. Each time the stool given by a mouse was recorded. The average of total number of stool given by the test group and the average of total number of stool given by the control group were compared. Percent inhibition of defecation in mice was calculated using the following equation:

Percent $(\%)$ inhibition $=\left\{\left(\mathrm{M}_{0}-\mathrm{M}\right) / \mathrm{M}_{0}\right\} \times 100$; where, Mo $=$ Mean defecation of control and $\mathrm{M}=$ Mean defecation of test sample.

Statistical analysis. All values are expressed as the mean \pm standard error of the mean (SEM) and the result were analyzed statistically by one-way analysis of variance (ANOVA) followed by Dunnett's test by using SPSS ver.16 (SPSS Inc., Chicago, IL), where $\mathrm{p}<0.05$ was considered to be statistically significant.

\section{RESULT AND DISCUSSION}

Phytochemical screening. Preliminary phytochemical screening of ethanolic extracts of the seeds of $S$. italica revealed the presence of various bioactive compounds like flavonoids, alkaloids, terpenoids, triterpenoids, tannins, phenolics and reducing sugar.

Table 1. Anti-microbial activity of seeds extracts of Setaria italica.

\begin{tabular}{|c|c|c|c|c|c|}
\hline \multirow[t]{2}{*}{ Test organisms } & \multicolumn{5}{|c|}{ Diameter of zone of inhibition (mm) } \\
\hline & CSI & PESI & CTSI & CFSI & Ciprofloxacin \\
\hline \multicolumn{6}{|l|}{ Gram positive Bacteria } \\
\hline Bacillus cereus & - & 11 & 10 & - & 42 \\
\hline B. megaterium & 12 & 11 & 10 & 10 & 45 \\
\hline B. subtilis & 12 & 12 & 10 & - & 40 \\
\hline Sarcina lutea & 12 & 12 & 10 & 9 & 42 \\
\hline Staphylococcus aureus & 12 & 12 & 12 & 9 & 42 \\
\hline \multicolumn{6}{|l|}{ Gram negative Bacteria } \\
\hline Escherichia coli & 13 & 12 & 11 & 9 & 41 \\
\hline Pseudomonas aeruginosa & 12 & 12 & 12 & 9 & 42 \\
\hline Salmonella paratyphi & 11 & 11 & 12 & 9 & 40 \\
\hline S. typhi & 11 & 12 & 11 & 10 & 42 \\
\hline Shigella boydii & 11 & 11 & 10 & 9 & 42 \\
\hline S. dysenteriae & 12 & 12 & 10 & 9 & 44 \\
\hline Vibrio mimicus & 13 & 13 & 11 & 9 & 42 \\
\hline V. parahemolyticus & 13 & 13 & 11 & - & 43 \\
\hline \multicolumn{6}{|l|}{ Fungi } \\
\hline Aspergillus niger & 12 & 12 & 11 & 9 & 42 \\
\hline Candida albicans & 13 & 12 & 13 & 10 & 42 \\
\hline Sacharomyces cerevacae & 13 & 13 & 13 & 10 & 40 \\
\hline
\end{tabular}


Table 2. Hypoglycemic activity of seed of Setaria italica.

\begin{tabular}{ccccc}
\hline Code & \multicolumn{4}{c}{ Plasma level of glucose (Mean \pm SEM) } \\
\cline { 2 - 4 } & 0 minute & 30 minute & 90 minute & 120 minute \\
\hline Control & $5.84 \pm 0.25$ & $10.12 \pm 0.29$ & $7.3 \pm 0.12$ & $5.72 \pm 0.21$ \\
Standard & $6.3 \pm 0.12$ & $3.72 \pm 0.28$ & $3.66 \pm 0.24$ & $3.44 \pm 0.15$ \\
CSI & $5.64 \pm 0.24$ & $4.10 \pm 0.39$ & $4.02 \pm 0.31$ & $3.74 \pm 0.24$ \\
PESI & $6.22 \pm 0.18$ & $7.30 \pm 0.07$ & $5.52 \pm 0.59$ & $4.76 \pm 0.35$ \\
CTSI & $5.18 \pm 0.08$ & $4.46 \pm 0.16$ & $4.0 \pm 0.36$ & $4.98 \pm 0.22$ \\
CFSI & $4.84 \pm 0.39$ & $4.74 \pm 0.07$ & $4.08 \pm 0.21$ & $3.72 \pm 0.11$ \\
\hline
\end{tabular}

Each value represents the mean \pm SEM, $(n=5) . P<0.01$ compared to control, Dunnett's test after analysis of variance.

Table 3. Effect of ethanolic extract of Setaria italica on castor oil induced diarrhea in mice.

\begin{tabular}{ccccc}
\hline Animal group & $\begin{array}{c}\text { Dose (per kg } \\
\text { body weight) }\end{array}$ & $\begin{array}{c}\text { Onset of diarrhea } \\
\text { Mean } \pm \text { SE (min) }\end{array}$ & $\begin{array}{c}\text { Number of diarrheal } \\
\text { episode } \\
\text { (Mean } \pm \text { SE) }\end{array}$ & $\begin{array}{c}\text { \% Inhibition of diarrheal } \\
\text { episode }\end{array}$ \\
\hline Control & Normal saline & $3.00 \pm 0.32$ & $16 \pm 1.15$ & - \\
Loperamide & $50 \mathrm{mg}$ & $66.60 \pm 2.94$ & $8 \pm .94^{*}$ & 56.32 \\
C2SI & $200 \mathrm{mg}$ & $8.0 \pm 0.41$ & $15 \pm 1.05$ & 6.25 \\
C4SI & $400 \mathrm{mg}$ & $11.0 \pm 0.52$ & $13 \pm 1.00$ & 18.75 \\
\hline
\end{tabular}

Values are expressed as mean \pm SEM $(n=5)$; One-way ANOVA; ${ }^{p} \mathrm{p}<0.001$ compared to control.

Assay of anti-microbial activity. The effects of ethanolic extract and different fractions generated from it on various microorganisms were observed to evaluate the anti-microbial activity (Table 1).

Assay of hypoglycemic activity. The effects of ethanolic extract of $S$. italica seeds and the different fractions to lower blood glucose level were observed to evaluate the hypoglycemic activity. The results are shown in table 2.

Assay of anti-diarrheal activity. The extractives revealed different degrees of anti-diarrheal activity as evident by the reduction of defecation (Table 3).

In anti-microbial assay by disc diffusion method, the ethanolic crude extract and different fractions of S. italica seeds showed mild anti-microbial activity against gram positive and gram negative bacteria and fungi (Table 1).

The ethanolic crude extract at $400 \mathrm{mg} / \mathrm{kg}$ body weight showed satisfactory hypoglycemic activity (5.64, 4.10, 4.02 and $3.74 \mathrm{mmol} / \mathrm{l}$ at 0, 30, 90 and 120 minute respectively, $\mathrm{P}<0.01$ ) as compared to the standard (6.3, 3.72, 3.66 and $3.44 \mathrm{mmol} / \mathrm{l}$ at $0,30,90$ and 120 minute respectively, $\quad \mathrm{P}<0.01$ ). The chloroform soluble fraction at $400 \mathrm{mg} / \mathrm{kg}$ body weight also revealed promising hypoglycemic activity. Previous study suggested that consumption of millets led to a significant decrease in serum glucose, serum lipids (serum cholesterol, TG and VLDL) and glycosylated hemoglobin (HbA1c) $)^{12-14}$ in type 2 diabetic rats. Thus, it can be concluded that the millets do have potential for a protective role in the management of diabetes.

In anti-diarrheal assay, the ethanolic crude extract of seeds of $S$. italica did not show any promising result. The study is only preliminary in nature and the extract can be studied in diarrheal mice before drawing any conclusive remark about the anti-diarrheal potency of the plant.

\section{CONCLUSION}

The present studies have shown that the ethanolic crude extract of $S$. italica and different fractions generated from it have promising anti-microbial and hypoglycemic properties. Further extensive studies are required to identify the possible phytoconstituents responsible for the above properties. 


\section{ACKNOWLEDGMENTS}

The authors acknowledge the help of Dhaka University Herberium for identification of the plant and Beximco Pharmaceutical Ltd, Bangladesh for supplying some standards and chemicals.

\section{REFERENCES}

1. Ghani, A. 2003. Medicinal plants of Bangladesh with chemical constituents and uses. Asiatic Society of Bangladesh, Dhaka, p. 387.

2. Bala, R.S. 2004. Neglected millets that save the poor from starvation. LEISA Ind, pp. 34-36.

3. Hitchcock, A.S. 1950. Manual of the Grasses of the United States. Dover Publications, New York.

4. Hafliger, E., and Scholz, H. 1981. Grass Weeds: Weeds of the subfamilies Chloridoideae, Pooideae, and Oryzoideae. CIBA-GEIGY Ltd., Basle, Switzerland.

5. Bailey, L.H. 1949. Manual of Cultivated Plants. The MacMillan Company, New York.

6. Leithead, H.L., Yarlett, L.L. and Shiflet, T.N. 1976. 100 native forage grasses in 11 southern states, Agriculture Handbook. Washington Soil Conservation Service, p. 389.
7. Vanwagenen, B.C., Larsen, R., Cardellina, J.H., Randazzo, D., Lidert, Z.C. and Swithenbank, C. 1993. Ulosantoin, a potent insecticide from the sponge Ulosa ruetleri. J. Org. Chem. 58, 335-337.

8. Trease, G.E. and Evans, W.C. 1989. A Text Book of Pharmacognosy. Cambridge University Press, London, UK.

9. Bauer, A.W., Kirby, W.M., M., Sherris, J.C. and Turck, M. 1966. Antibiotic susceptibility testing by a standardized single disc method. Am. J. Clin. Pathol. 45, 493-96.

10. Trinder, P.1969. Determination of glucose in blood using glucose oxidase. J. Ann. Clin. Biochem. 6, 24-25.

11. Shoba, F.G. and Thomas, M. 2001. Study of anti-diarrheal activity of four medicinal plants in castor-oil induced diarrhea. J. Ethnopharmacol. 76, 73-76.

12. Lamba, S., Buch, K., Lewis, H. and Lamba, J. 2000. Phytochemicals as potential hypoglycemic agents. J. Chem. Pharma. Bull. 21, 457-497.

13. Husen, R., Pihie, A. and Nallappan, M. 2004. Screening for antihyperglycaemic activity in several local herbs of Malaysia. J. Ethnopharmacol. 95, 205-208.

14. Saroja, R. and Mohan, V. 1990. Current concepts in diet and diabetes. Ind. J. Nutr. Diet. 36, 193. 